ISSN: 2146-0574, eISSN: 2536-4618

Makina Mühendisliği / Mechanical Engineering

DOI: 10.21597/jist.811215 Araştırma Makalesi / Research Article

Geliş tarihi / Received: 15-10-2020

Kabul tarihi / Accepted: 03-11-2020

Doğal Elyaf Takviyeli Grafen Nanoplatelet Dolgulu Epoksi Matrisli Kompozitlerde Abrazif Aşınma

Yusuf Eren ERDOĞDU ${ }^{1 *}$, Şemsettin TEMIZZ ${ }^{1}$

ÖZET: Son yıllarda düşük maliyet, biyobozunurluk, hafiflik gibi özelliklerinden dolayı doğal elyaf takviyeli kompozitler bazı alanlarda sentetik elyaf takviyeli kompozitlere alternatif hale gelmiştir. Bu çalışmada, vakum destekli reçine transfer kalıplama (VDRTK) metodu ile üretilen jüt kumaş takviyeli ve farklı dolgu oranlarında (ağırlıç̧a \% 0, 0.5, 1, 2) grafen nanoplatelet (GNP) dolgusu yapılmış epoksi matrisli kompozitlere abrazif aşınma testleri uygulanmıştır. Tribotestler pim-disk tipi tribotest cihazı kullanılarak 400 grit SiC zımpara kağıdı karşı yüzeyi üzerinde $5 \mathrm{~N}, 10 \mathrm{~N}$ ve $15 \mathrm{~N}$ yüklerde $1 \mathrm{~m} \mathrm{~s}^{-1} \mathrm{kayma}$ hızında ve $200 \mathrm{~m}$ kayma mesafesinde gerçekleştirilmiştir. Yapılan testlerde ara yüzey sıcaklığı ve spesifik aşınma oranı değerleri takip edilmiştir. Spesifik aşınma oranının ağırlıkça \%1 GNP dolgusunda minimum olduğu ve ara yüzey sıcaklığının genel olarak artan yük ile arttığı görülmüştür.

Anahtar Kelimeler: Doğal elyaf takviyeli polimer kompozit (DETPK), grafen nanoplatelet (GNP) dolgu, abrazif aşınma.

\title{
Abrasive Wear on Natural Fiber Reinforced Graphene Nanoplatelets Filled Epoxy Matrix Composites
}

ABSTRACT: In recent years, natural fiber reinforced composites have become an alternative to synthetic fiber reinforced composites in some areas due to their properties like low cost, biodegradability and lightness. In this study, abrasive wear tests were applied to jute fabric reinforced epoxy matrix composites filled with graphene nanoplatelets (GNPs) at different filling ratios $(0,0.5,1,2$ wt.\%), produced with vacuum assisted resin transfer molding (VARTM) method. Tribotests were carried out using a pin-on-disk type tribotest device on the counterface of 400 grit SiC emery paper with $5 \mathrm{~N}, 10 \mathrm{~N}$ and $15 \mathrm{~N}$ loads at a sliding speed of $1 \mathrm{~m} \mathrm{~s}^{-1}$ and a sliding distance of $200 \mathrm{~m}$. In the tests carried out, the interface temperature and specific wear rate values were followed. It has been found that the specific wear rate is minimal at $1 \mathrm{wt} \%$ GNPs filler and the interface temperature generally increases with increasing load.

Keywords: Natural fiber reinforced polimer composite (NFRPC), grafen nanoplatelets (GNPs) filler, abrasive wear.

${ }^{1}$ Yusuf Eren ERDOĞDU (Orcid ID: 0000-0003-3255-8466), Şemsettin TEMIZ (Orcid ID: 0000-0002-67373720), İnönü Üniversitesi, Mühendislik Fakültesi, Makina Mühendisliği Bölümü, Malatya, Türkiye

*Sorumlu Yazar/Corresponding Author: Yusuf Eren ERDOĞDU, e-mail: eren.erdogdu@inonu.edu.tr 


\section{GİRIŞ}

Kompozit malzemeler, en az iki ayrı fiziksel fazın birleşmesiyle oluşan ve bileşen malzemelerinden farklı olarak karışık özellikler gösteren malzeme sistemidir. Kompozit malzemelerle polimer, seramik veya metallerle tek başına elde edilemeyecek karma özellikler elde edilebilir (Groover, 2010). Bir bileşen takviye fazı olarak adlandırılır ve takviye fazının içine gömüldüğü faza ise matris adı verilir. Takviye fazı malzemesi elyaflar, parçacıklar veya pullar halinde olabilir ve matris fazı malzemeleri genellikle sürekli malzemelerdir (Kaw, 2006). Fiziksel ve mekanik özellikler, kompozit imalatı sırasında katı dolgu malzemesinin matris gövdesine dahil edilmesiyle daha da değiştirilebilir (Patnaik ve Nayak, 2018). Kompozitlerde takviye, elyaflar ve dolgu maddeleri şeklinde olabilir. Elyaflar matrise güç sağlayıp kompozitlerin mekanik özelliklerini arttırırken dolgu maddeleri ise sertliği, termal direnci, stabiliteyi, mukavemeti, aşınma direncini, gözenekliliği ve termal genleşme katsayısını artırır. Dolgular ana bileşenler de olabilir elyaflara ek olarak da eklenebilir. Ayrıca hemen hemen her temel reçine özelliğini değiştirebilir veya elyaflı kompozitin özelliklerini artırabilir. Kompozitlerde istenen özellikleri elde etmek için uygun elyaf ve dolgu maddesi seçimi önemlidir (Agarwal ve ark., 2014).

Polimer kompozitlerin kullanımının yaygınlaşmasıyla birlikte, özellikle kullanım ömrünü tamamlayan elemanların yarattığı çevresel kirlilik büyük bir sorun haline gelmiştir. Bu nedenle son yıllarda polimer kompozitlerin kütlelerinin tamamının veya bir kısmının biyobozunur malzemelerden üretilmesine yönelik çok sayıda çalışma yürütülmüştür (Nirmal ve ark., 2012; Bajpai ve ark., 2013; Shuhimi ve ark., 2016; Deepak ve ark., 2017; Babu ve ark., 2018). Doğal elyafların polimer kompozitlerde takviye olarak tercih edilmesinde biyobozunurluk özelliğinin yanında özellikle düşük maliyet, hafiflik, imalat kolaylığı, işleme ekipmanına karşı düşük abrazif etki gibi önemli avantajlara sahip olmasının da payı büyüktür (Yousif and El-Tayeb, 2009; Nirmal ve ark., 2015). Ancak doğal elyaf takviyeli kompozit malzemeler, cam elyafı gibi geleneksel sentetik takviyelerle üretilen kompozitlere göre daha düşük mekanik özelliklere sahiptir. Bu nedenle sentetik elyaflarla üretilen kompozitlerle sadece mobilya, mimari paneller, spor malzemeleri ve otomotiv iç bileşenleri gibi yapısal olmayan uygulamalarda yarışabilirler (Ramadan ve ark., 2017). Bu nedenle doğal elyaf takviyeli kompozitlerin özelliklerini sentetik elyaf takviyeli kompozitlerle yapısal anlamda yarışabilir hale getirmek için çeşitli dolgular kullanılarak modifiye edilmesi işlemi güncelliğini koruyan ve araştırmacıların dikkatini çeken bir konudur. Doğal elyaflar arasında yüksek başlangıç mukavemeti ve sekant modülü, iyi boyutsal kararlılık, yüksek pürüzlülük katsayısı, kullanım kolaylığı, kopmada düşük uzama gibi ayırt edici özellikleri nedeniyle en popüler olanı jüt elyaftır (Ahmed ve ark., 2012). Diğer yandan, GNP de tribolojik uygulamalarda popülerdir. 2 boyutlu katmanlar arasındaki zayıf Van der Waals kuvveti, çok katmanlı grafende katmanlar arasında kaymanın kolaylaşmasına neden olarak sürtünme katsayısında azalmaya yol açtığından bu benzersiz özellik, araştırmacıları tribolojik uygulamalardaki grafenin potansiyelini değerlendirme konusunda motive etmektedir (Lahiri ve ark., 2014).

$\mathrm{Bu}$ çalışmada doğal elyaf olan düz örgü (plain) tipi jüt kumaş takviyeli, dolgusuz (\%0 GNP) ve ağırlıkça \%0.5, 1, 2 GNP dolgulu epoksi matrisli kompozitlerin farklı yükler altında abrazif aşınma davranışları incelenmiştir.

\section{MATERYAL VE METOT}

\section{Üretim Materyali}

Çalışmada kompozit üretiminde doğal elyaf takviye malzemesi olarak Ganges Jute Private Limited firmasından alınan ve $313 \mathrm{gr} \mathrm{m}^{-2}$ yoğunluklu düz örgü tipi jüt kumaş kullanılırken, matris malzemesi olarak Nanografi Türkiye'den alınan ve özellikleri Çizelge 1'de gösterilen Huntsman Araldite LY 5052 epoksi reçine ve Aradur LY 5052 sertleştirici kullanılmıştır. Matrisi modifiye etmek için Nanografi 
Türkiye'den alınan \%99.5 saflıkta, $24 \mu \mathrm{m}$ çapında ve $6 \mathrm{~nm}$ kalınlığında $150 \mathrm{~m}^{2} \mathrm{~g}^{-1}$ özgül yüzey alanına sahip GNP kullanılmıştır.

Çizelge 1. Reçine ve sertleştirici komponentlere ait özellikler (Anonim, 2012)

\begin{tabular}{ccccc}
\hline Komponent & Çekme modülü (GPa) & Poisson oranı & Viskozite (mPaS) & Yoğunluk $\left(\mathrm{gr} \mathrm{cm}^{-3}\right)$ \\
\hline A: Araldite LY 5052 & $3-3.2^{*}$ & $0.35^{*}$ & $1000-1500$ & 1.17 \\
B: Aradur LY 5052 & & & $40-60$ & 0.94 \\
\hline
\end{tabular}

*:(A ve B'nin karışımı)

\section{Kompozit Üretimi}

Jüt kumaşlar 330 mm ayrıt uzunluğunda kare şeklinde kesildikten sonra kolay şekil alabilmesi ve dokusundaki tozlardan arındırılması amacıyla şebeke suyunda yıkandıktan sonra 5 gün oda sıcaklığında kurumaya bırakılmıştır. Daha sonra 8 kat şeklinde üst üste dizilen kumaşlar vakum destekli reçine transfer işlemi için Şekil 1'deki gibi paketlenmiştir.

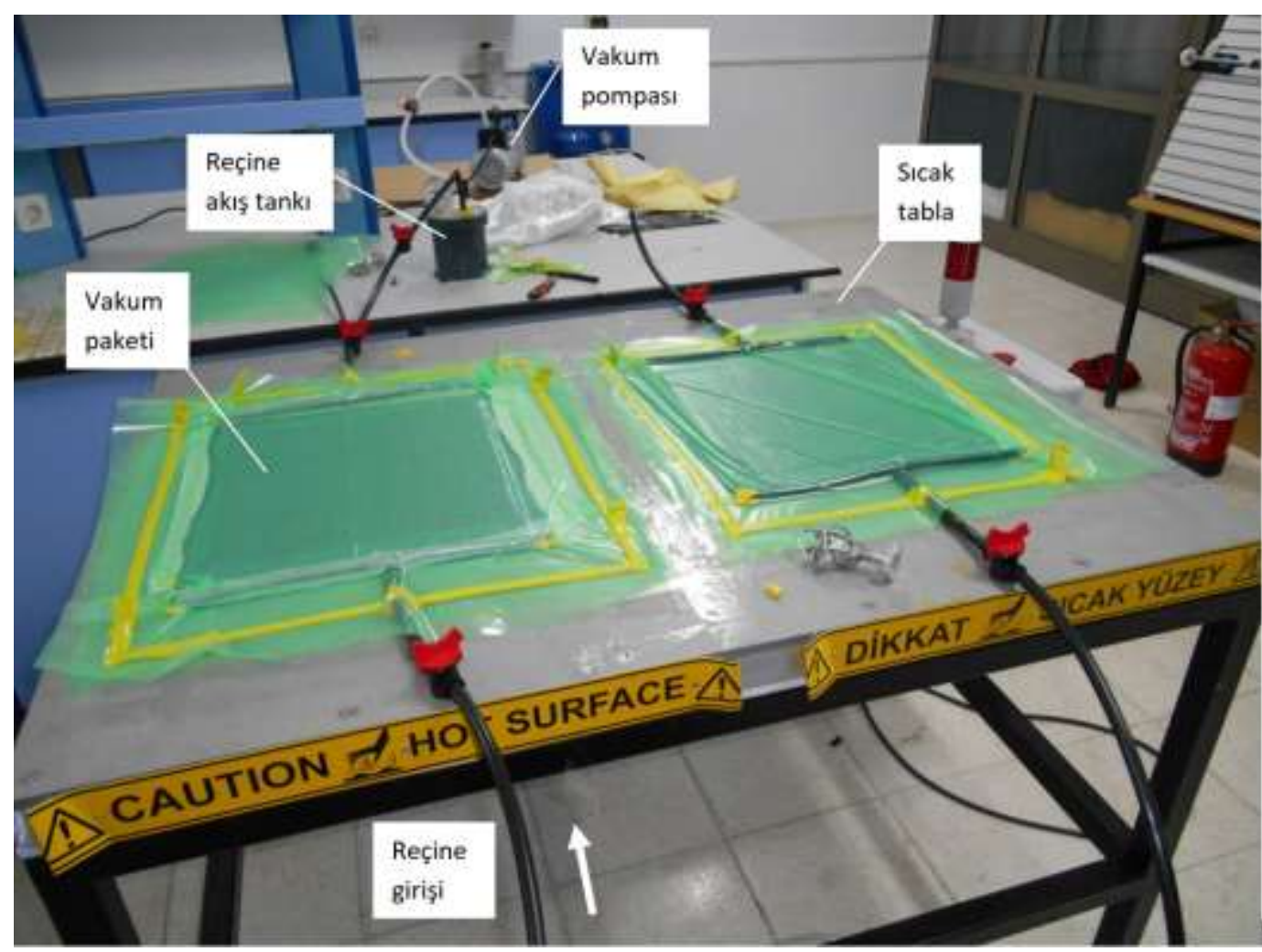

Şekil 1. Vakum destekli reçine transfer işlemi

Epoksi ağırlıkça \%72.5 ve sertleştirici ise \% 27.5 oranlarında karıştırıldıktan sonra sisteme verilerek işlem başlatılmıştır. GNP dolgusu yapılan modifiye edilmiş reçinelerde ise önce ağırlıkça \%0.5, 1, 2 oranlarında GNP toz halde Araldite LY5052'ye eklendikten sonra IKA RW 20 dijital karıştırıcı ile 1000 devir dakika $^{-1}$ 'da 10 dakika boyunca karıştırılarak reçineye dağılımı sağlanmıştır. Daha sonra GNP karışmış reçineye sertleştirici ilave edilerek aynı hızda 30 saniye daha karıştırıldıktan sonra vakum destekli reçine transfer işlemine geçilmiştir. İşlemden sonra vakum paketi sıcak tabla üzerinde $80^{\circ} \mathrm{C}$ 'de 16 saat boyunca kürlenmeye bırakılmıştır. Kürlenme işlemi bittikten sonra kompozit hazır halde paketten çıkarılmıştır. 


\section{Aşınma Testleri}

Üretilen kompozit plakalar dekupaj testere yardımıyla daha küçük plakalar şeklinde kesildikten sonra By Laser EBH CNC lazer kesim tezgahında $\varnothing 10 \mathrm{~mm}$ boyutlarında aşınma numuneleri kesilmiştir (Şekil 2).

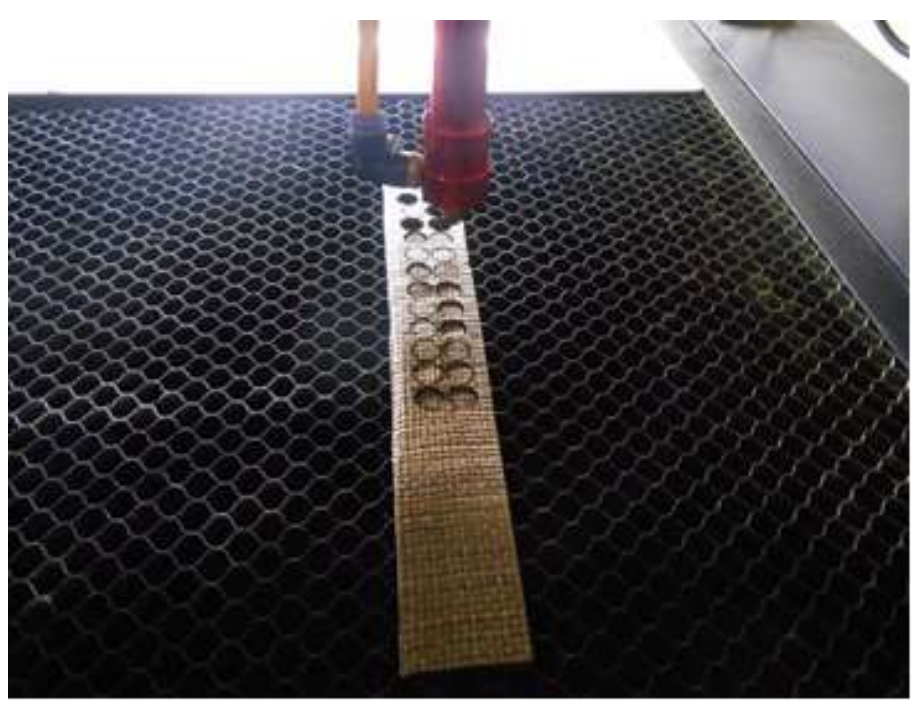

Şekil 2. Üretilen kompozit plakadan CNC lazer ile aşınma numunesi kesimi

Aşınma testleri için hazırlanan numunelerde test sonrası aşınma oranı hesabı yapılması için yoğunluk tayini yapılmıştır. Her bir plakadan kesilen numuneler için ayrı ayrı olacak şekilde rastgele seçilen numuneler için $0.1 \mathrm{mg}$ hassasiyetine sahip Necklife FA 2004 hassas terazi yardımıyla kütle ölçülmüş ve bu numuneler içinde saf su bulunan $0.1 \mathrm{ml}$ hassasiyetinde dereceli kaba atılarak hacimleri ölçülmüştür. Daha sonra ölçülen kütle değerleri ölçülen hacim değerlerine bölünerek numunelerin yoğunlukları hesaplanmıştır. Kesilen numuneleri aşınma cihazına bağlayabilmek için düşük karbonlu çelik çubuktan $\varnothing 10 \times 12 \mathrm{~mm}$ boyutlarında pimler torna tezgahında kesilerek hazırlanmıştır. Çelik pim ve kompozit aşındırma numuneleri BETA Kimya Mitre apel adhezifle birbirine yapıştırıldıktan sonra aşınma testine hazır hale gelmiştir (Şekil 3).

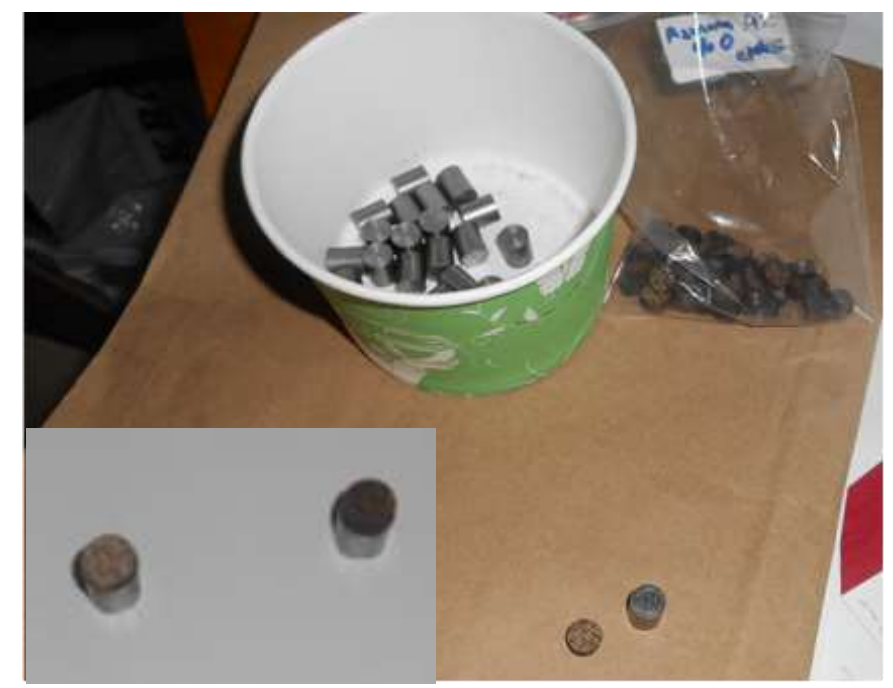

Şekil 3. Hazırlanan çelik pimler ve aşınma numuneleri

Aşınma numuneleri hazırlandıktan sonra sürtünme olayının diğer tarafı olan abrazif karşı yüzey hazırlanmıştır. Bunun için çelik disk yüzeyine BETA Kimya Mitre apel adhezifle 400 grit Hermes WS 
Flex 18 C P 400 SiC zımpara kağıdı yapıştırılmıştır. Zımpara kağıdının yüzey pürüzlülüğü Time TR 3200 pürüzlülük ölçer ile numune uzunluğu $0.8 \mathrm{~mm}$, pürüzlülük değerlendirme uzunluğu $4 \mathrm{~mm}$ olacak şekilde ölçülmüş ve Time 3200 -EN(1.0) programı yardımıyla pürüzlülük eğrileri alınmıştır. Son olarak Şekil 4'te gösterilen TURKYUS POD aşınma cihazı üzerinde 5,10 ve $15 \mathrm{~N}$ yükler altında $200 \mathrm{~m}$ kayma mesafesinde ve $1 \mathrm{~m} \mathrm{~s}^{-1}$ kayma hızında abrazif aşınma deneyleri yürütülmüştür.

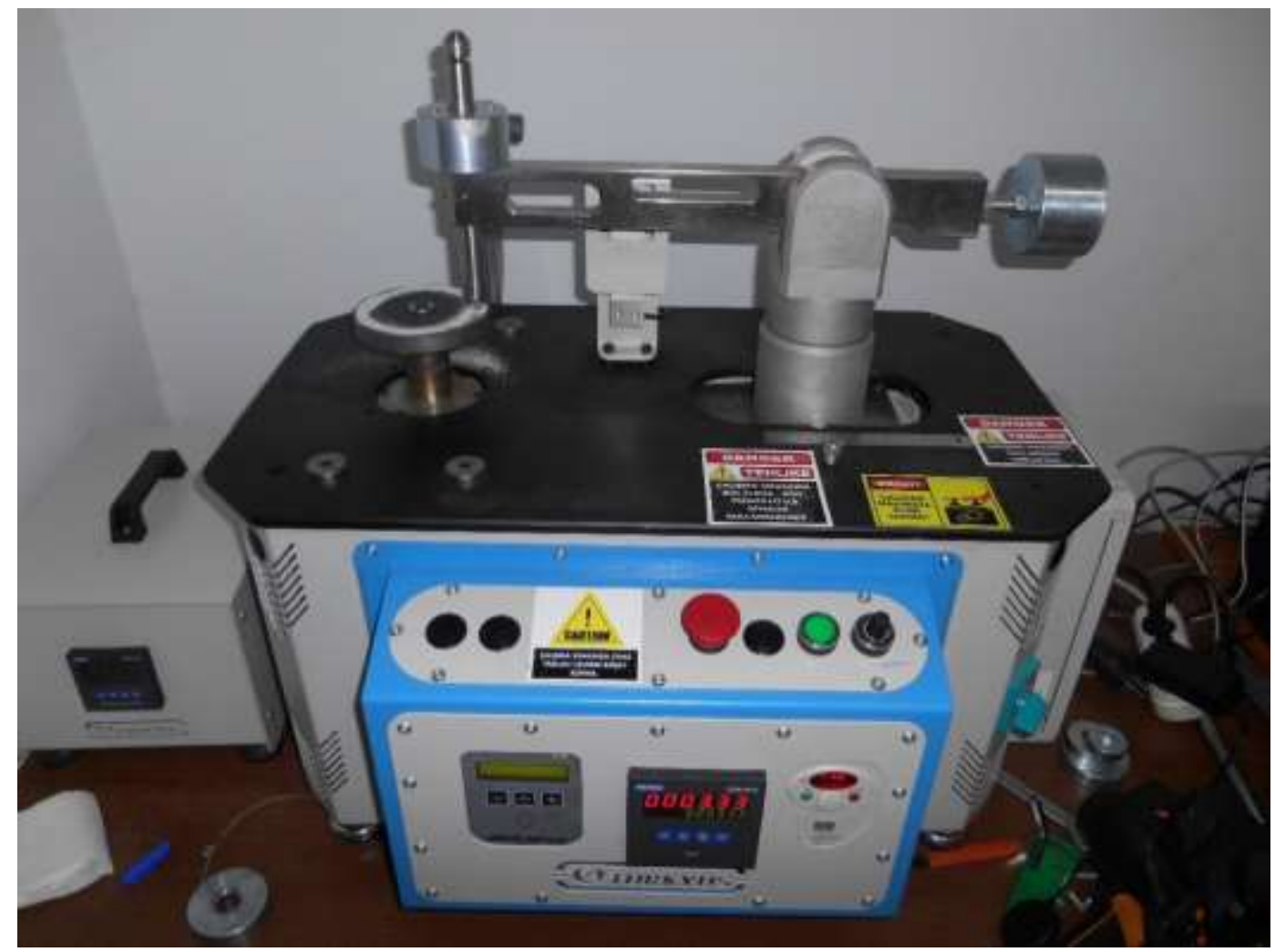

Şekil 4. Aşınma deney düzeneği

Her bir deney yaklaşık 3 dakika 33 saniye boyunca sürmüş ve deneylerde Testo 875-1i termal kamera ile $30 \mathrm{sn}$ aralıklarla sürtünmeli yüzeylerin termal görüntüleri alınarak ara yüzeydeki maksimum sıcaklığa sahip noktaların sıcaklıkları işaretlenerek takip edilmiştir (Şekil 5).
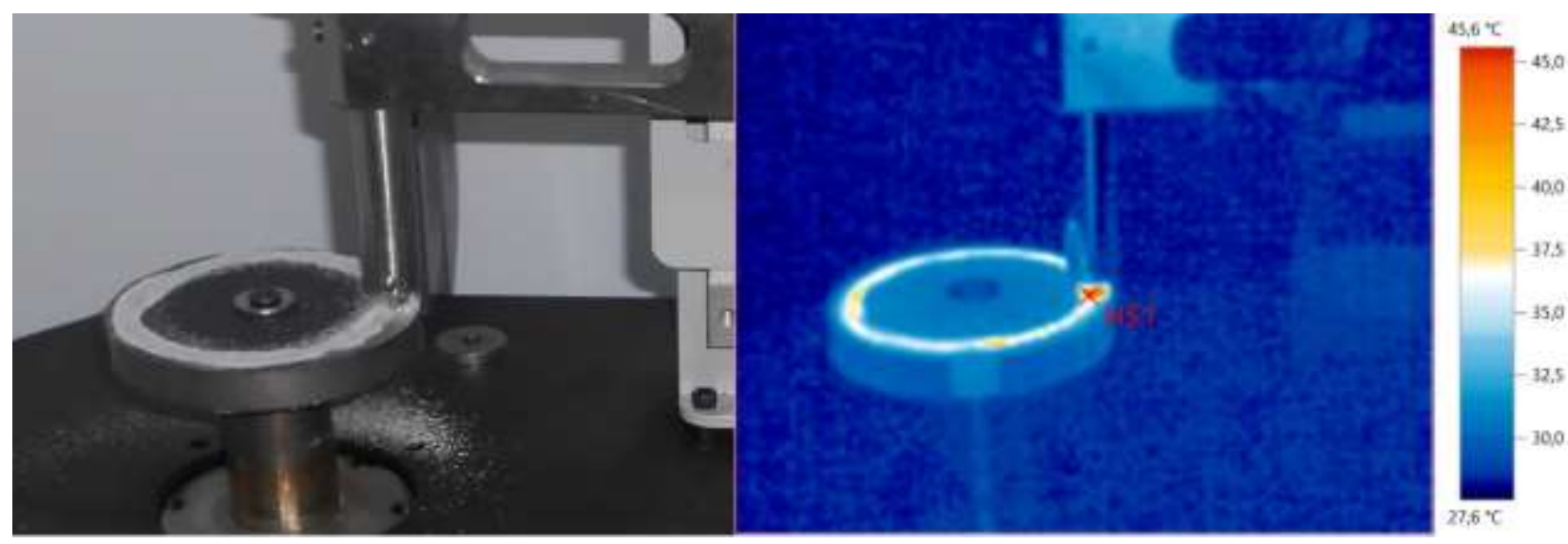

Şekil 5. Ara yüzey sıcaklığı̈ ölçümü 
Her bir numune için test öncesinde ve test sonrasında Necklife FA 2004 hassas terazi ile $0.1 \mathrm{mg}$ hassasiyetinde ölçüm yapılarak aşınan kütle $(\Delta \mathrm{m})$ hesaplanmıştır. Daha sonra bu veriler yardımıyla spesifik aşınma oranı $(\mathrm{W})$ değerleri hesaplanmıştır.

$$
W=\frac{\Delta m}{\rho N L}
$$

$\rho:$ yoğunluk $\left(\mathrm{gr} \mathrm{cm}^{-3}\right)$

$\mathrm{N}$ : yük $(\mathrm{N})$

L: kayma mesafesi (m)

Abrazif aşınma testleri bitiminde sürtünmeli temasa maruz kalan yüzeylerden TriLine 2Mp USB stereo mikroskop ile görüntüler alınmış ve yorumlanmıştır.

\section{BULGULAR VE TARTIŞMA}

Yürütülen çalışmada karşı yüzey olarak kullanılan SiC zımpara kağıdına ait yüzey pürüzlülüğü değerleri Çizelge 2'de verilmiştir. Ayrıca ortalamaya en yakın ölçüme ait pürüzlülük eğrisi grafiği Şekil 6'da gösterilmiştir. Çizelge 2 ve Şekil 6'daki verilere bakıldığında karşı yüzeyin aşındırıcılığının üniforma yakın ve tutarlı sonuçlar almaya elverişli olduğu görülmektedir.

Çizelge 2. Yüzey pürüzlülüğü ölçüm değerleri

\begin{tabular}{ccccccc}
\hline Ölçüm no & $\mathbf{1}$ & $\mathbf{2}$ & $\mathbf{3}$ & $\mathbf{4}$ & $\mathbf{5}$ & Ortalama \\
\hline $\operatorname{Ra}(\boldsymbol{\mu m})$ & 7.357 & 6.205 & 7.305 & 7.973 & 5.702 & 6.908 \\
\hline
\end{tabular}

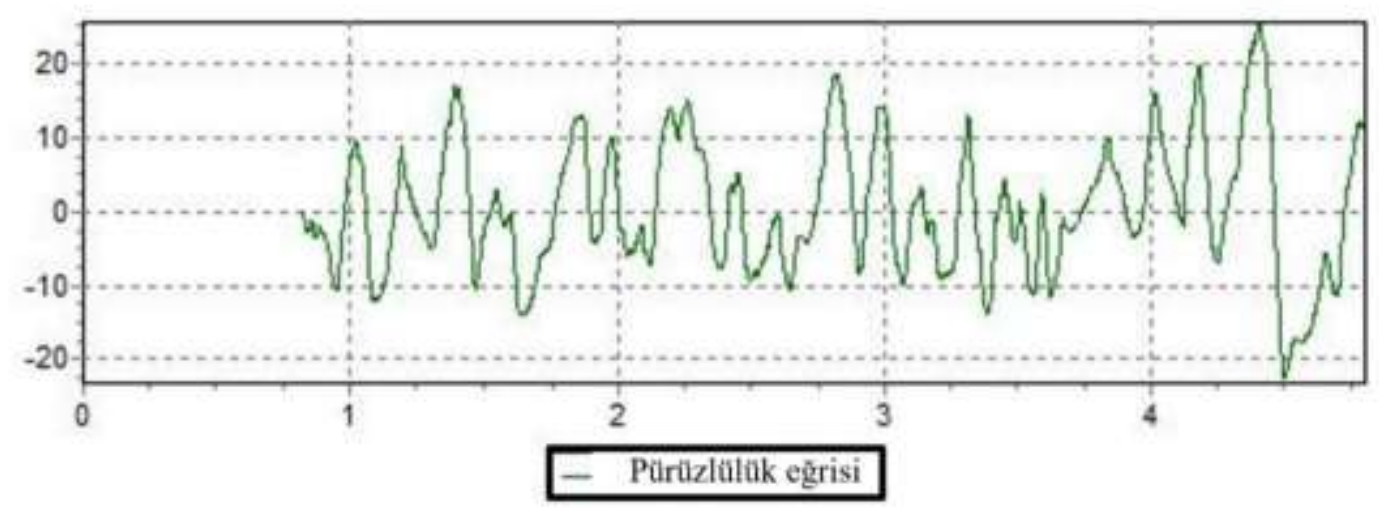

Şekil 6. Çekme testi sonrası numune örnekleri

Aşınma, bir çok parametreye bağlı karmaşık bir olgu olduğundan spesifik aşınma oranı değerlerine bakılarak yorumlanması daha doğru sonuçlar vermektedir. Spesifik aşınma oranının hesaplanmasında yoğunluk parametresine ihtiyaç duyulmaktadır. Farklı dolgu oranlarındaki numunelerin hesaplanan yoğunluk değerleri Çizelge 3'de verilmiştir. Çalışmada yürütülen testlere ait yüke bağlı spesifik aşınma oranı grafiği Şekil 7'de sunulmuştur.

Çizelge 3. Numunelerin hesaplanan yoğunlukları

\begin{tabular}{ccccc}
\hline Dolgu oranı & \%0 GNP & \%0.5 GNP & \%1 GNP & \%2 GNP \\
\hline Yoğunluk $\left(\mathrm{gr} \mathrm{cm}^{-\mathbf{3}}\right)$ & 0.9740 & 1.2985 & 1.1909 & 1.0356 \\
\hline
\end{tabular}


Çizelge 3'e bakıldığında GNP dolgusu yapılmasının numune yoğunluğunu artırdığı ancak GNP dolgu oranının artmasıyla birlikte numune yoğunluğunda azalma olduğu görülmektedir. GNP dolgu oranı arttıkça viskozite arttığından ve aglomerasyon yaşandığından malzeme içinde hava boşlukları oluşmakta ve bu durum da yoğunluğu düşürmektedir.

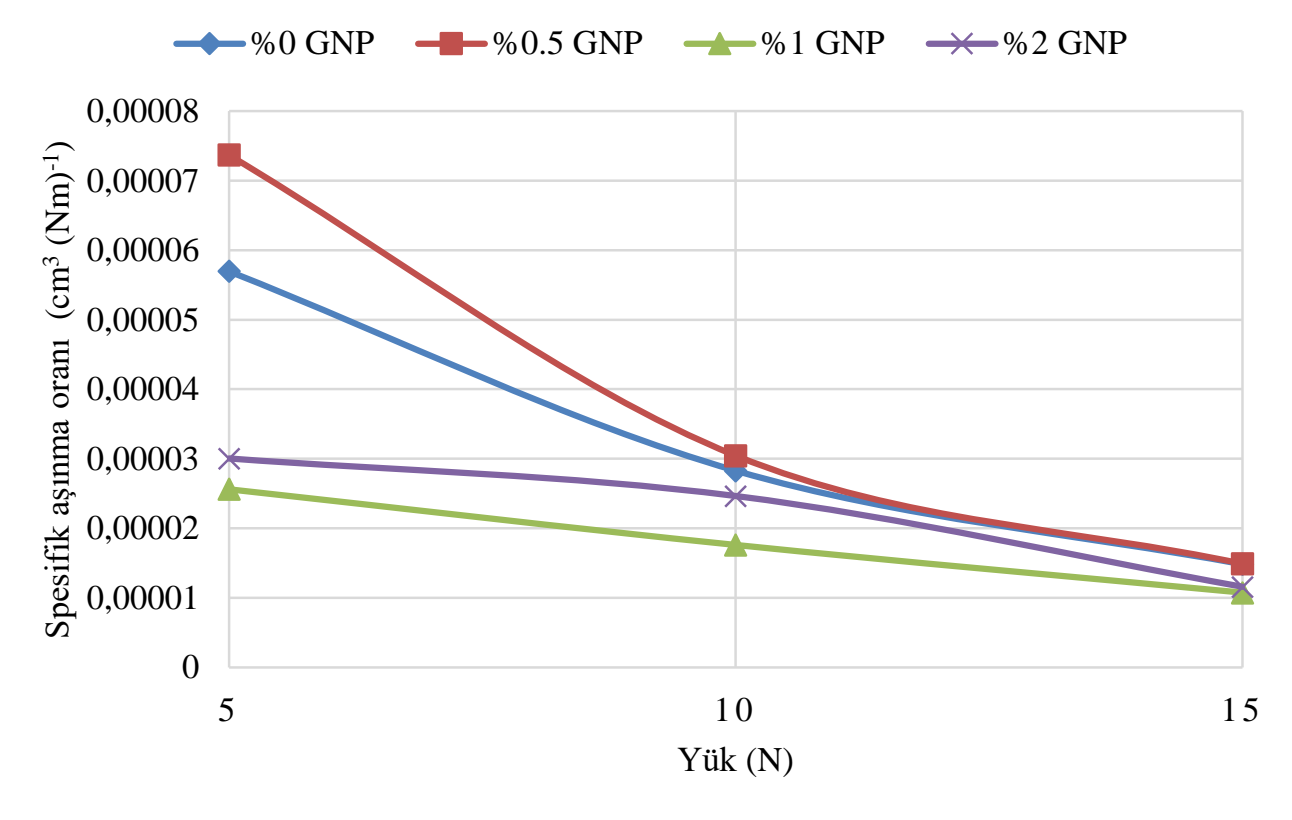

Şekil 7. Yüke bağlı spesifik aşınma oranı grafiği

Şekil 7'de numunelerin spesifik aşınma oranlarına bakıldığında \%1 GNP dolgusu yapmanın aşınma direnci açısından en optimum koşulları sağladığı görülmektedir. \%0.5 GNP dolgusunda ise aşınma direncinin dolgusuz numunelere göre daha düşük olduğu görülmektedir. Ancak, uygulanan yük arttıkça \%0.5 GNP dolgulu numunelerin spesifik aşınma oranı değerleri dolgusuz numunelere yaklaşmaktadır. Ayrıca yük artııça spesifik aşınma oranının ayırt edici özelliğinin azaldığı ve eğrilerin eğilimine bakıldığında literatürdeki başka çalışmalarla benzer şekilde ( Kumar ve ark., 2020)15 N yükten daha büyük yüklerde kıyaslamalarda kullanmanın belirleyici olmadığı görülmektedir. Şekil 7'deki sonuçlar değerlendirilirken iki hususa dikkat etmek gerekir:

Birincisi, GNP dolgusu yapılınca viskozitenin artmasına (Erdoğdu ve ark., 2018) bağlı olarak boşlukların oluşması ve matris ile takviye elyaflar arasındaki arayüz yapışmasının azalmasına neden olmaktadır. Bunun sonucunda aşınmaya bağlı kopma hasarları oluşmakta ve aşınma döküntüsü kütlesi artmaktadır. Şekil 8'de a)'dan d)'ye doğru gidildikçe eliptik bölgelerle gösterilen boşluklu yapının ve kesikli eliptik bölgelerle gösterilen aşınmaya bağlı kopma hasarlarının arttığı görülmektedir.

İkinci olarak da GNP'nin sürtünme katsayısını düşürücü etkisi olduğundan (Lahiri ve ark., 2014) aşınma direnci sağlamaktadır. \%2 GNP dolgusu yapılmış numunelerde boşluklu yapının çok fazla olmasına karşın spesifik aşınma oranın düşük olduğu görülmektedir. Bu durum, ikinci tespitin birinciden baskın olmasıyla açıklanabilir.

Şekil 8'de tüm numunelerde aşınma yönüne paralel çizgilenmeler göze çarpmaktadır. Bu çizgiler pulluklanma mekanizmasının baskın olduğunu göstermektedir. Ayrıca, görünen beyaz bölgeler boşluklara aşınma döküntülerinin dolmasıyla oluşmuştur. Şekil 8 d)'ye bakıldığında, bu bölgeler toplam yüzeyin yarıya yakın kısmını oluşturmaktadır. Bu da GNP dolgu oranının artmasıyla birlikte temas yüzeyi alanının azaldığını ve dolayısıyla temas yüzeyi basıncının arttığını göstermektedir. Artan yüzey 
basıncı, uygulanan yükün etkisini artırdığından aşınma açısından dezavantajlı bir durum oluşturmaktadır. GNP dolgusunun neden olduğu tüm dezavantajlara rağmen, GNP'nin aşınma direncini artırması nedeniyle \%2 GNP dolgusu yapılan numunelerde beklenilenden dahi iyi sonuçlara ulaşılmıştır.

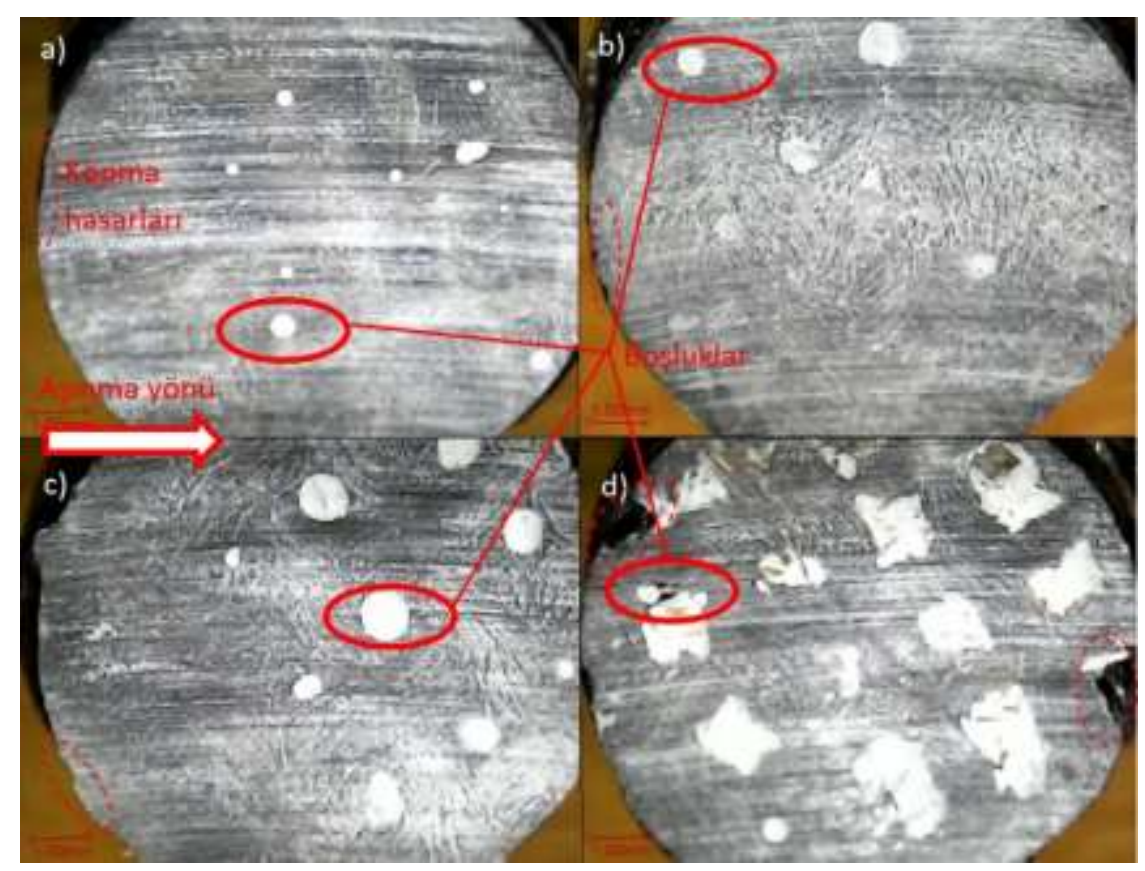

Şekil 8. $10 \mathrm{~N}$ yük altında aşınan numunelerin yüzey görüntüleri a) $\% 0 \mathrm{GNP}$, b) $\% 0.5 \mathrm{GNP}$, c) $\% 1 \mathrm{GNP}$, d) $\% 2 \mathrm{GNP}$

Yapılan deneylerde tüm numunelerde kısa süre içinde aşındırıcı zımpara kağıdı yüzeylerinin Şekil 9'da görüldüğü gibi aşınma döküntülerinin oluşturduğu bir tabakayla kaplandığ1 gözlemlenmiştir. Bu sayede abrazif yüzeyin aşındırıcı etkisi kısmen azalmıştır. Ayrıca Şekil 9'da eliptik bölgelere bakıldığında sıvanan aşınma ürününün yüzeye zarar vermeden aşındırıcıdan yer yer ayrıldığı görülmektedir. Bu bölgelerde abrazif yüzey tekrar devreye girerek aşındırmaya devam etmektedir.

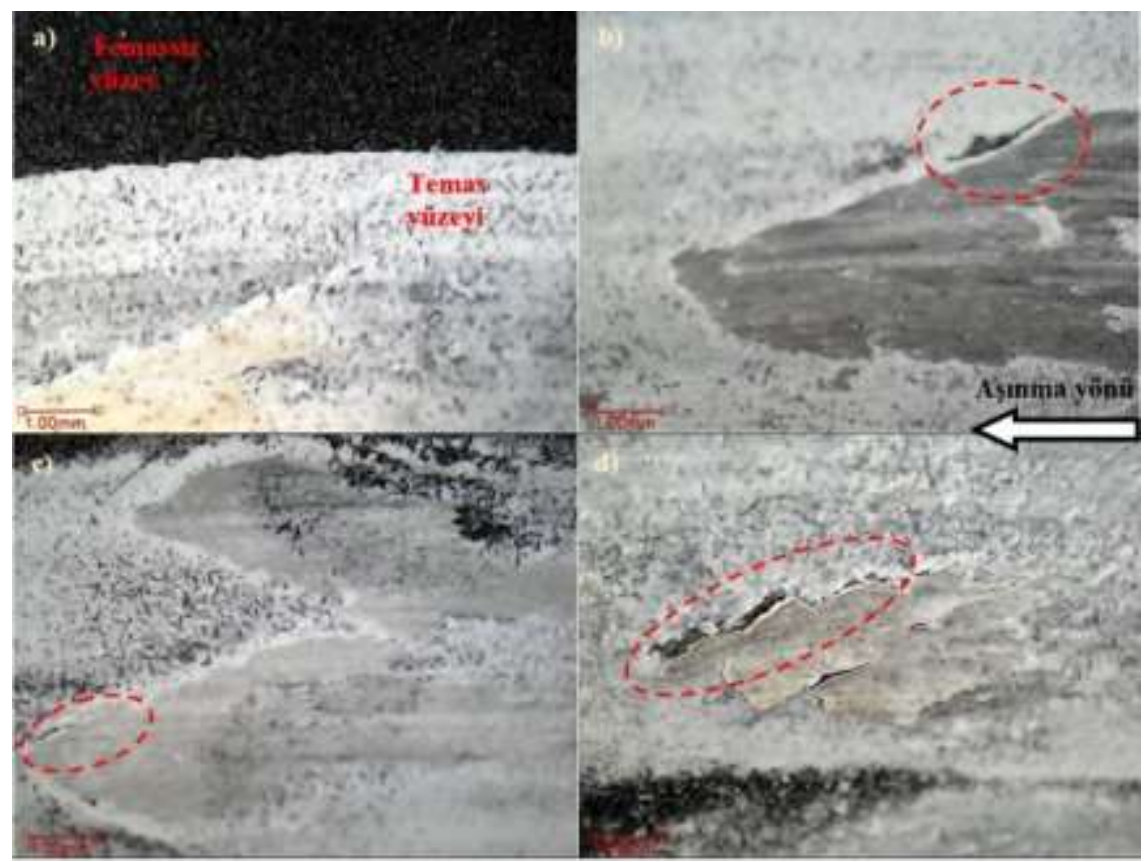

Şekil 9. $10 \mathrm{~N}$ yük altında abrazif karşı yüzeye ait görüntüler a) $\% 0 \mathrm{GNP}$, b) $\% 0.5 \mathrm{GNP}$, c) $\% 1 \mathrm{GNP}$, d) $\% 2 \mathrm{GNP}$ 
Abrazif aşınma deneylerinde takip edilen diğer bir parametre de sürtünmeli temasın olduğu ara yüzey sıcaklığıdır. Numunelerin ara yüzey sıcaklıkları Şekil 10'da sunulmuştur. Ara yüzey sıcaklığının genellikle artan yük ile birlikte arttığı, GNP dolgusunun ise düzenli bir etki oluşturmadığı görülmektedir. Kayma mesafesine bakıldığında ise; başlangıçta ara yüzey sıcaklığı artan kayma mesafesiyle yükselirken daha sonra abrazif taneciklerin arasının kompozit malzemeyle dolması ve 1sıl dengeye ulaşılması nedeniyle belirgin değişimler gözlenmemiştir. Oda sıcaklığında yapılan deneylerde sürtünmeli ara yüzeye ait en düşük sıcaklık $36^{\circ} \mathrm{C}$ iken en yüksek sıcaklık $73.6^{\circ} \mathrm{C}$ olarak ölçülmüsstür. Bu sıcaklık aralığı kompozit malzemede yapısal olarak değişikliğe neden olacak düzeyde değildir ancak artan sıcaklığın Şekil 9'da gösterilen aşınma döküntülerinin sıvanmasıyla oluşmuş nispeten kaygan yüzeyin geliştirdiği aşınma direncine katkısı olduğu düşünülmektedir.

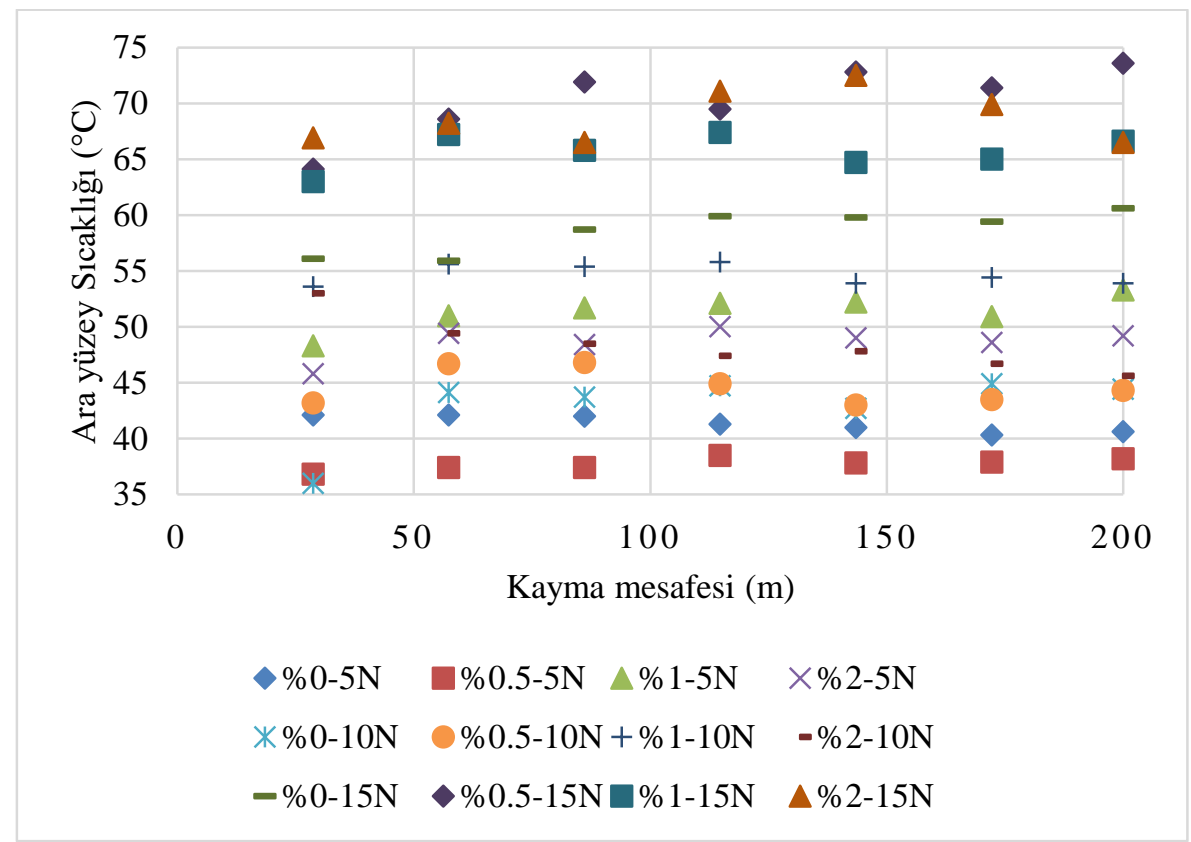

Şekil 10. Mesafeye bağlı ara yüzey sıcaklığı grafiği

\section{SONUÇ}

Yürütülen çalışmada VDRTK ile üretilen jüt kumaş takviyeli ve farklı oranlarda GNP dolgusu yapılmış epoksi matrisli kompozit numunelerin farklı yükler altında abrazif aşınma davranışları incelenmiş ve spesifik aşınma oranları kıyaslanarak farklı oranlarda GNP dolgusu yapmanın malzemenin tribolojik özelliklerine etkisi incelenmiştir. Çalışma bitiminde ulaşılan sonuçlar şunlardır:

* $\quad$ Ara yüzey sıcaklığı genellikle artan yükle birlikte artmaktadır.

* GNP dolgusu yapmak bir yandan sürtünme kuvvetini azaltıcı etki yaparken diğer yandan boşluklu yapıya ve elyaf-matris arayüz yapışmasının azalmasına neden olmaktadır.

* GNP dolgusu yapmak aşınmayı genel olarak azaltmaktadır. Ağırlıkça \%1 oranında GNP dolgusu yapmak daha ideal bir aşınma direnci yaratmaktadır.

* Matrise GNP dolgu yapılmasıyla viskozite artışına bağlı boşluk oluşumu gibi üretimde ortaya çıkan olumsuzluklar azaltılabilirse GNP'nin sürtünme kuvvetini azaltıcı etkisi daha belirgin şekilde ortaya çıkarak iyi bir aşınma direnci sağlayacağı düşünülmektedir. Bunu sağlamak için daha küçük boyutlu GNP kullanılması önerilmektedir. 


\section{TEŞEKKÜR}

$\mathrm{Bu}$ çalışma, İnönü Üniversitesi Bilimsel Araştırma Projeleri Koordinasyon Birimi tarafindan "FBA-2019-1750" kodlu proje ile desteklenmiştir.

\section{KAYNAKLAR}

Agarwal G, Patnaik A, Sharma RK, 2014. Thermo-mechanical properties and abrasive wear behavior of silicon carbide filled woven glass fiber composites. Silicon, 6.3:155-168.

Ahmed KS, Khalid SS, Mallinatha V, Kumar SJA, 2012. Dry sliding wear behavior of SiC/A12O3 filled jute/epoxy composites. Materials \& Design (1980-2015), 36:306-315.

Anonim, 2012. Advanced Materials Araldite ${ }^{\circledR} L Y 5052$ / Aradur ${ }^{\circledR 5052}$ Cold Curing Epoxy Systems. https://samaro.fr/pdf/FT/Araldite_FT_LY_5052_Aradur_5052_EN.pdf(Erişim Tarihi: 10.10.2020).

Babu TN, Singh R, Dogra S, 2018. Wear characteristics of epoxy resin based composites reinforced with aloe fibers in combination with Al2O3/SiC. Materials Today: Proceedings, 5.5:12649-12656.

Bajpai PK, Singh I, Madaan J, 2013. Tribological behavior of natural fiber reinforced PLA composites. Wear, 297.1-2: 829-840.

Deepak P, Sivaraman H, Vimal R, Badrinarayanan S, Vignesh Kumar R, 2017. Study of wear properties of jute/banana fibres reinforced molybdenum disulphide modified epoxy composites. Materials Today: Proceedings, 4.2:2910-2919.

Erdoğdu YE, Korkmaz EE, Önal T, Önal Y, Temiz Ş, 2018. Epoksi reçinede partikül takviye oranının viskozite ve sıcaklık değişimine etkisinin araştırılması. 1. Uluslararası Battalgazi Multi Disipliner Çalışmalar Kongresi, 7-9 Aralik 2018, Malatya.

Groover MP, 2010. Fundamentals of Modern Manufacturing. Wiley, 187, The USA.

Kaw AK, 2006. Mechanics of Composite Materials. Taylor \& Francis Group, 2, The USA.

Kumar S, Singh KK, Ramkumar J, 2020. Comparative study of the influence of graphene nanoplatelets filler on the mechanical and tribological behavior of glass fabric-reinforced epoxy composites. Polymer Composites, 2020:1-15.

Lahiri D, Hec F, Thiesse M, Durygin A, Zhang C, Agarwal A, 2014. Nanotribological behavior of graphene nanoplatelet reinforced ultra high molecular weight polyethylene composites. Tribology International, 70:165-169.

Nirmal U, Hashim J, Low KO, 2012. Adhesive wear and frictional performance of bamboo fibres reinforced epoxy composite. Tribology International, 47:122-133.

Nirmal U, Hashim J, Megat Ahmad MMH, 2015. A review on tribological performance of natural fibre polymeric composites. Tribology International, 83:77-104.

Patnaik TK, Nayak SS, 2018. Development of silicon carbide reinforced jute epoxy composites: Physical, mechanical and thermo-mechanical characterizations. Silicon, 10.1:137-145.

Ramadan N, Taha I, Hammouda R, Abdellatif MH, 2017. Behaviour of hybrid SiC/Jute epoxy compositesmanufactured by vacuum assisted resin infusion. Polymers \& Polymer Composites, 25.5:333344.

Shuhimi FF, Abdollah MFB, Kalam MA, Hassan M, Mustafa A, Amiruddin H, 2016. Tribological characteristics comparison for oil palm fibre/epoxy and kenaf fibre/epoxy composites under dry sliding conditions. Tribology International, 101:247-254.

Yousif BF, El-Tayeb NSM, 2009. Mechanical and wear properties of oil palm and glass fibres reinforced polyester composites. International Journal of Precision Technology, 1.2:213-222. 